Open Access

\title{
The combined molecular adjuvant CASAC enhances the CD8+ T cell response to a tumor-associated self-antigen in aged, immunosenescent mice
}

Gee Jun Tye ${ }^{1,2+}$, Kyriaki loannou ${ }^{1 \dagger}$, Eunice Amofah ${ }^{1}$, Ruby Quartey-Papafio ${ }^{1}$, Samantha J. Westrop ${ }^{1}$, Pramila Krishnamurthy ${ }^{1}$, Alistair Noble ${ }^{3}$, Phillip M. Harrison ${ }^{4}$, Karin M.L. Gaensler ${ }^{5}$, Linda D. Barber ${ }^{1 *}$ and Farzin Farzaneh ${ }^{*}$

\begin{abstract}
Background: Ineffective induction of T cell mediated immunity in older individuals remains a persistent challenge for vaccine development. Thus, there is a need for more efficient and sophisticated adjuvants that will complement novel vaccine strategies for the elderly. To this end, we have investigated a previously optimized, combined molecular adjuvant, CASAC (Combined Adjuvant for Synergistic Activation of Cellular immunity), incorporating two complementary Toll-like receptor agonists, CpG and polyl:C, a class-II epitope, and interferon (IFN)- $\gamma$ in aged mice.

Findings: In aged mice with typical features of immunosenescence, antigen specific CD8+ T cell responses were stimulated after serial vaccinations with CASAC or Complete/Incomplete Freund's Adjuvant (CFA/IFA) and a class I epitope, deriving either from ovalbumin (SIINFEKL, SIL) or the melanoma-associated self-antigen, tyrosinase-related protein-2 (SVYDFFWLL, SVL). Pentamer analysis revealed that aged, CASAC/SIL-vaccinated animals had substantially higher frequencies of $\mathrm{H}-2 \mathrm{~K}^{\mathrm{b}} / \mathrm{SIL}$-specific CD8+ T cells compared to the CFA/IFA-vaccinated groups. Similarly, higher frequencies of $\mathrm{H}-2 \mathrm{~K}^{\mathrm{b}} / \mathrm{SVL}$-pentamer+ and IFN- $\gamma+\mathrm{CD} 8+\mathrm{T}$ cells were detected in the aged, CASAC + SVL-vaccinated mice than in their CFA/IFA-vaccinated counterparts. In both antigen settings, CASAC promoted significantly better functional CD8+ T cell activity.

Conclusion: These studies demonstrate that functional CD8+ T cells, specific for both foreign and tumourassociated self-antigens, can be effectively induced in aged immunosenescent mice using the novel multi-factorial adjuvant CASAC.
\end{abstract}

Keywords: Immunotherapy, Vaccine, adjuvant, TLR, Immunosenescence, Ageing

\section{Findings}

Introduction

The sequelae of immunosenescence in older individuals, including increased morbidity and mortality from infection and malignancy, represent a critically important public health problem [1]. As a consequence of accumulated dysfunctions in the immune system during ageing,

\footnotetext{
* Correspondence: linda.barber@kcl.ac.uk; farzin.farzaneh@kcl.ac.uk ${ }^{\dagger}$ Equal contributors

'Department of Haematological Medicine, King's College London, Rayne Institute, London, UK

Full list of author information is available at the end of the article
}

vaccination of older individuals is less efficacious than in the young $[2,3]$. Previous attempts to increase vaccination efficacy by incorporating various adjuvants, including alum, have shown only modest success [2]. Thus, there is an unmet need for new vaccine strategies for the elderly.

Immunosenescence is characterised by decline in both adaptive and innate immune functions [4, 5]. Innate immune responses are activated, mainly, by stimulation of Toll-like receptors (TLRs) [6], the expression and function of which declines with age [7]. Dendritic cells (DCs) from both young and aged individuals exhibit 
comparable activation in response to most TLR ligands, and are equally capable of direct and cross-presentation of antigens to $\mathrm{T}$ cells in vitro [8], underscoring the likely importance of TLR-induced DC activation in promoting adaptive immunity. TLR stimulation is therefore a promising strategy to enhance vaccine efficacy in the elderly. Combinations of TLR agonists may be especially effective, as demonstrated in animal models and clinical trials $[6,9-13]$.

We previously showed that triggering of multiple TLRs, using a combined adjuvant for synergistic activation of cellular immunity (CASAC), incorporating CpG, polyI:C, interferon (IFN)- $\gamma$ and MHC-class I and II peptides, results in potent cytotoxic $\mathrm{T}$ cell-mediated immunity in young mice [14]. Optimization of the adjuvant formulation and investigation of mechanism of action were also performed [14]. We now report the ability of CASAC to improve vaccination-induced responses in aged mice by promoting induction of antigen-specific cellular immunity to both foreign and self tumourassociated peptide antigens.

\section{Methods}

\section{Animals and vaccination procedures}

Young (6-8 weeks old) and aged (18-22 months old) wild-type C57BL/6 female mice were purchased from Harlan, UK. All animal procedures were performed according to UK Home Office and institutional regulations.

CASAC vaccine comprised of an oil-in-water emulsion consisting of Tween-80 and squalene (all Sigma, UK), as previously described [14]. The tween/squalene mixture was sonicated and mixed at a 1:1 ratio with PBS containing: $50 \mu \mathrm{g}$ polyl:C (TLR3 agonist; Sigma), $25 \mu \mathrm{g}$ CpG 1826 (TLR9 agonist; Eurofins, UK), 100 ng mouse recombinant IFN- $\gamma$ (Peprotech, UK), $100 \mu \mathrm{g}$ ISQAVHAAHAEINEAGR (ovalbumin (OVA)-derived MHC-class II $\left(\mathrm{H}_{-2} \mathrm{IA}^{\mathrm{b}}\right)$-restricted peptide) and $100 \mu \mathrm{g}$ SIINFEKL (SIL; OVA-derived MHC-class I ( $\left.\mathrm{H}-2 \mathrm{~K}^{\mathrm{b}}\right)$-restricted peptide) or SVYDFFVWL (SVL; tyrosinase related protein (TRP)2-derived MHC-class I ( $\left.\mathrm{H}-2 \mathrm{~K}^{\mathrm{b}}\right)$-restricted peptide; all PPR, UK). Alternatively, $100 \mu \mathrm{g}$ of SIL or SVL was emulsified with Complete Freund's Adjuvant (CFA) for the first vaccination, and Incomplete FA (IFA; all Sigma) for subsequent vaccinations at a 1:1 ( $\mathrm{vol} / \mathrm{vol})$ ratio. All vaccine formulations were administered intradermally on days $0,10,20$ and 30 ( \pm 1 day) in $100 \mu \mathrm{L}$ final volume (50 $\mu \mathrm{L} /$ flank).

\section{Flow cytometric analysis}

Cell enumeration was performed in whole blood samples using Flow-Count ${ }^{\text {tw }}$ beads (Beckman Coulter, UK) according to manufacturer's instructions. After red blood cell lysis, mononuclear cells were stained with anti-CD3/ eFluor 450, anti-CD4/FITC and anti-CD8a/PerCP-Cy5.5 monoclonal antibodies (mAb) (all eBioscience, USA). Expression of PD-1, KLRG1 and LAG-3 was assessed in whole blood samples after staining with anti-CD3/eFluor 450, anti-CD8a/PerCP-Cy5.5, anti-PD-1/FITC, KLRG-1/ APC and anti-LAG-3/PE mAbs (all eBioscience). Pentamer analysis was performed as previously described [14], using $\mathrm{H}-2 \mathrm{~K}^{\mathrm{b}} / \mathrm{SIINFEKL}$ or $\mathrm{H}-2 \mathrm{~K}^{\mathrm{b}} / \mathrm{SVYDFFVWL}$ Pro5 pentamer/PE (ProImmune, UK).

To assess peptide-induced intracellular accumulation of IFN- $\gamma$ by CD8+ T cells, splenocytes were stimulated with $1 \mu \mathrm{g} / \mathrm{mL}$ SVL peptide, $0.5 \mu \mathrm{g} / \mathrm{mL}$ co-stimulatory anti-CD28 antibody (eBioscience) in the presence of GolgiPlug (BD Biosciences, Belgium) for $5 \mathrm{~h}$ prior to fixation, permeabilization, and staining with anti-CD3/eFluor 450, anti-CD8a/PerCp-Cy5.5 and anti-IFN- $/$ PE mAbs (eBioscience).

Samples were analysed using a FACSCantoII (BD Biosciences) and FACSDiva (BD Biosciences) or FlowJo (Treestar, OR) software.

\section{In vivo cytotoxicity assay}

The in vivo cytotoxicity assay was performed as previously described [14].

\section{Statistical analysis}

The Mann-Whitney $U$ test (GraphPad Prism, USA) was used to compare distributions, with $\mathrm{p}<0.05$ considered significant.

\section{Results and discussion}

Previous studies have shown that immunosenescence associated with increasing age is especially pronounced within the $\mathrm{T}$ cell compartment [15-17]. Consistent with these reports, aged C57BL/6 mice used in our study had significantly lower CD4+ (median 270 cells/ $\mu \mathrm{L}$ blood) and CD8+ (median 189 cells $/ \mu \mathrm{L}$ of blood) $\mathrm{T}$ cell numbers, compared to young mice (1527 $\mathrm{CD} 4+/ \mu \mathrm{L}$ blood; $p<$ 0.0001 and $1067 \mathrm{CD} 8+/ \mu \mathrm{L}$ blood; $p<0.0001$ ) (Fig. 1a). $\mathrm{CD} 4+$ and $\mathrm{CD} 8+\mathrm{T}$ cell percentages were also decreased significantly in aged (median 10.8 and $6.2 \%$ of all lymphocytes, respectively), compared to young mice (30.00\%; $p<0.0001$ and $20.90 \% ; p<0.0001$, respectively) (Fig. 1b). Expression of PD-1, KLRG-1 and LAG-3, indicative of $T$ cell exhaustion and anergy $[18,19]$, was significantly elevated on CD8 $+\mathrm{T}$ cells in aged mice (Fig. 1c) compared to young counterparts.

\section{CASAC enhances responses to a foreign antigenic CD8+ T cell epitope in aged mice}

CASAC was previously shown to effectively promote $\mathrm{T}$ cell immunity to the foreign antigen OVA in young mice [14]. We therefore investigated whether CASAC augments responses to the immunogenic OVA peptide SIL [20] in aged mice, compared to CFA/IFA as a conventional 

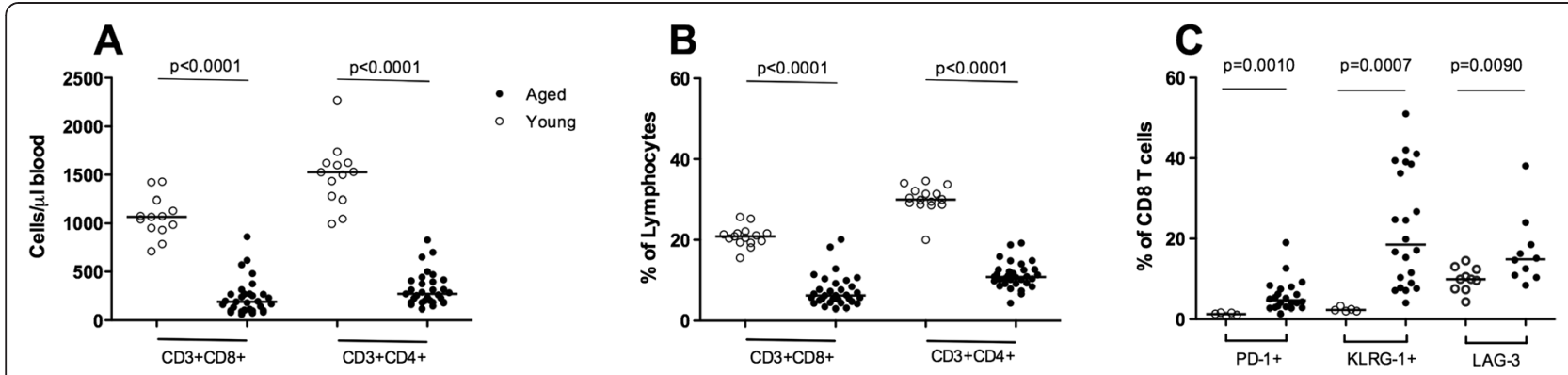

Fig. 1 Age-associated differences in peripheral blood T cell subsets. The absolute numbers (a) and percentages (b) of CD4+ and CD8+ T cells were determined in blood samples from young (open circles) and aged (filled circles) C57BL/6 mice by flow cytometric analysis using counting beads. c Expression of PD-1, KLRG-1 and LAG-3 on CD8+ T cells in young and aged mice. Each symbol represents an individual mouse and the median is indicated by a horizontal line. Data is pooled from 2 independent experiments. The Mann-Whitney $U$ test was used to compare distributions

adjuvant control [21]. Using our previously described vaccination protocol [14], young and aged C57BL/6 mice were vaccinated twice at a 10-day interval with SIL, combined either with CFA/IFA or CASAC. The distribution of percentages of $\mathrm{H}-2 \mathrm{~K}^{\mathrm{b}} / \mathrm{SIL}$-pentamer+ $\mathrm{CD} 8+\mathrm{T}$ cells was significantly higher $(p=0.0003)$ in the CASAC-vaccinated group (median $14.55 \%$ ), compared to CFA/IFA vaccinations $(0.80 \%)$. As shown previously [14], distribution of $\mathrm{H}-2 \mathrm{~K}^{\mathrm{b}} / \mathrm{SIL}-$ pentamer+ $\mathrm{CD} 8+\mathrm{T}$ cell frequencies was also found to be significantly higher $(p=0.0002)$ in young mice vaccinated with CASAC (median $13.80 \%$ ), compared to their CFA/IFA-treated counterparts (0.29\%). Of importance, the $\mathrm{H}-2 \mathrm{~K}^{\mathrm{b}} / \mathrm{SIL}$-pentamer+ $\mathrm{CD} 8+\mathrm{T}$ cell frequencies induced by CASAC vaccinations in both young and aged mice were similar. Although similar percentages were induced in both CASAC-vaccinated cohorts, the absolute numbers of SIL-specific CD8+ T cells (Fig. $2 b)$ showed a significantly lower $(p=0.0033)$ distribution in aged mice (median 22.30) compared to their young counterparts (396.3). This was due to the lower total numbers of CD8+ $\mathrm{T}$ cells in aged mice (Fig. 1a). The function of SIL-specific $\mathrm{T}$ cells was assessed by performing in vivo cytolytic assays. Aged mice vaccinated with CASAC showed higher distribution of antigen-specific cytolytic activity (median $88.5 \%$; Fig. 2c) compared to the CFA/IFA-vaccinated mice (16.8 \%; $p=0.0106)$. Similar outcomes were observed in the young groups $(98.0$ and $58.1 \%$ for CASAC and CFA/IFA vaccinated groups, respectively; $p=0.0238$ ). These results show that CASAC effectively induced CD8+ T cell mediated immunity to a foreign antigen in both aged and young mice.

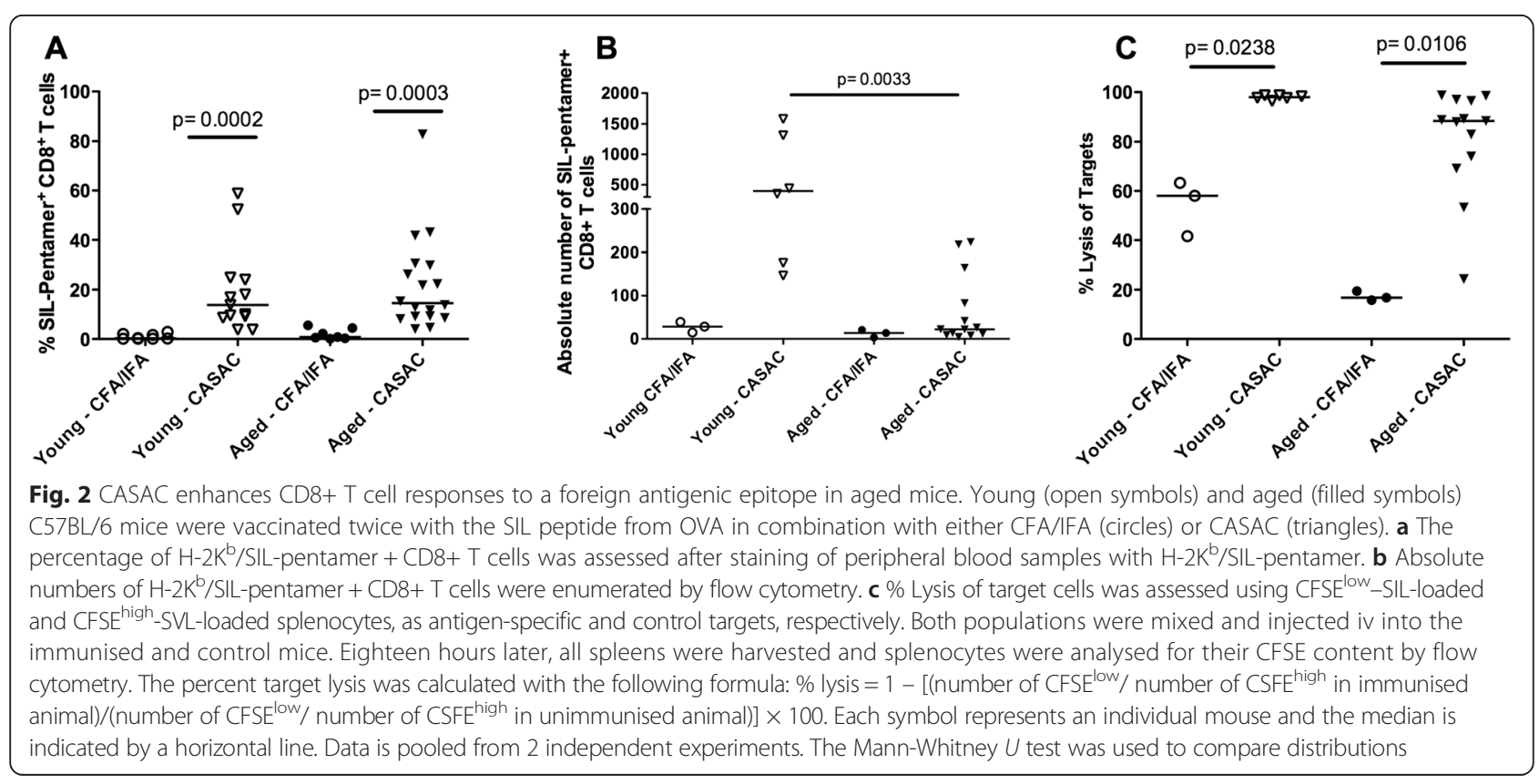




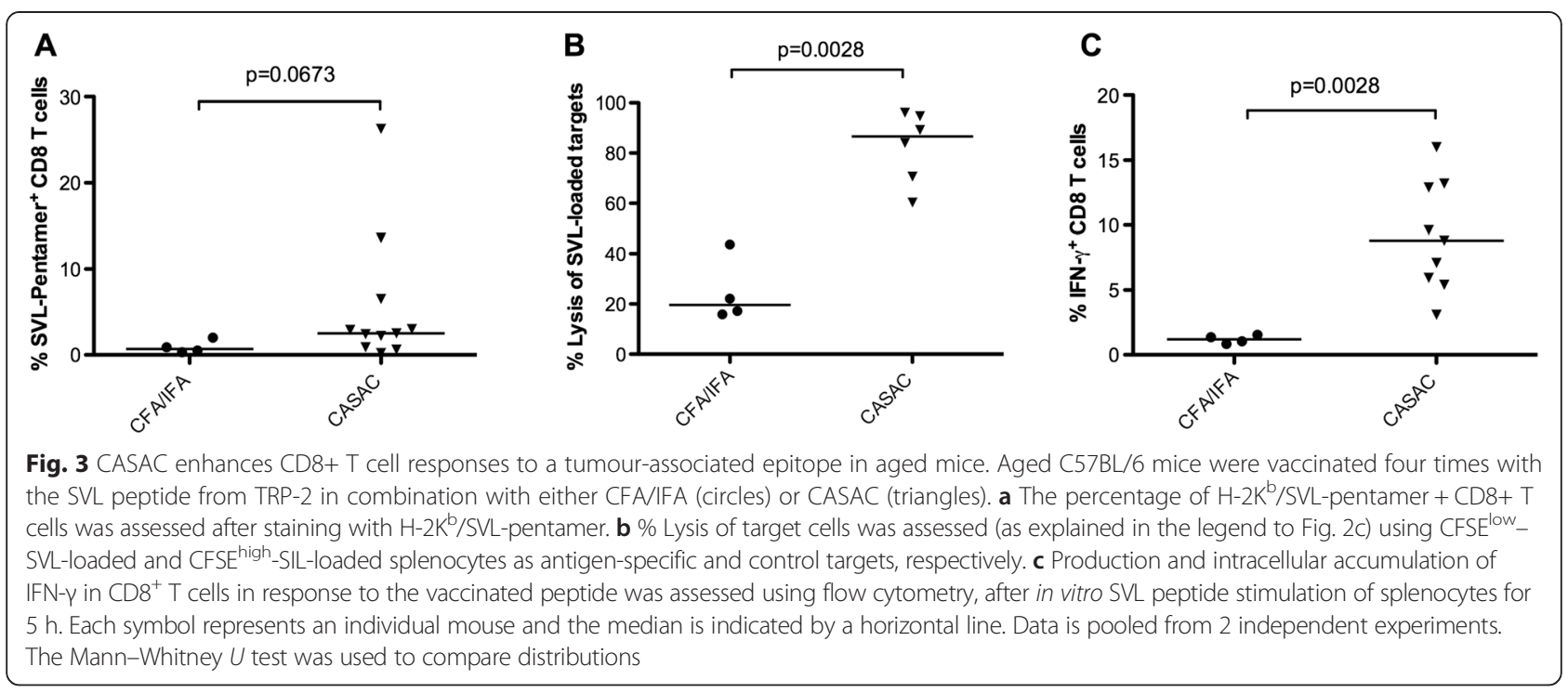

CASAC enhances responses to a tumor-associated CD8+ T cell epitope in the aged mice

The need for efficient vaccine adjuvants applies not only to infectious disease but also to cancer, a disease with increasing age-associated incidence [22]. It is therefore imperative that new adjuvants incorporated in anticancer vaccines are assessed for efficacy in aged immunosenescent individuals.

We have previously shown that immune tolerance to the melanoma-associated self-antigen TRP-2 can be overcome by vaccination of young mice with the TRP-2 peptide SVL combined with CASAC [14]. Functional SVL-specific CD8+ T cells were detected after two rounds of vaccinations; however, responses were of variable magnitude and required vaccination with the higher peptide dose of $400 \mu$ g. We therefore performed further optimization studies in young mice and found four rounds of vaccination, using $100 \mu \mathrm{g}$ SVL peptide with CASAC, consistently induced higher frequencies of SVL-specific CD8+ T cells (data not shown). All studies with aged mice were performed with four rounds of vaccination using $100 \mu \mathrm{g}$ SVL peptide in combination with either CASAC or CFA/IFA. Distribution of SVL-specific CD8+ T cell frequencies was higher in the SVL +CASAC-vaccinated group (median $2.5 \%$ ) compared to the SVL + CFA/IFAvaccinated group $(0.7 \%)$, although the difference did not reach statistical significance $(p=0.0673$; Fig. 3a). In vivo cytotoxicity studies (Fig. 3b) showed that lysis of SVLloaded splenocytes was significantly higher in SVL + CASAC-vaccinated (median $86.6 \%$ ) compared to SVL + CFA/IFA-vaccinated aged mice (median $19.7 \% ; p=$ $0.0028)$. Additionally, distribution of IFN- $\gamma+\mathrm{CD} 8+\mathrm{T}$ cell frequencies after in vitro SVL peptide stimulation was significantly higher in the SVL + CASAC-vaccinated mice (median $8.9 \%$; Fig. 3c) compared to CFA/IFA-vaccinated mice $(1.2 \% ; p=0.0028)$. Thus, vaccination of aged mice with the tumour-associated SVL peptide and CASAC induced antigen-specific CD8+ T cells that had considerably better functional activity than $\mathrm{CD} 8+\mathrm{T}$ cells induced by SVL + CFA/IFA-vaccination.

In conclusion, we have demonstrated that our combined molecular adjuvant CASAC effectively promotes functional antigen-specific $\mathrm{CD} 8+\mathrm{T}$ cell responses to vaccination with peptides in aged mice, despite their immunosenescent phenotype. CASAC improved responses in aged mice not only to a highly immunogenic foreign antigen, but also to the tumour-associated selfantigen TRP-2 whose immunogenicity is being evaluated in clinical trials [23]. Restoration of response to vaccination in immunosenescent aged mice by CASAC likely reflects the benefits of multiple TLR triggering on DC function $[14,24,25]$ and provision of IFN- $\gamma$ could substitute for lack of IFN- $\gamma$ from CD8+ memory cells during the early phase of immune response. Since CASAC comprises a combination of agents that individually are approved for human use, our findings suggest that a CASAC-based vaccination strategy may be amenable to rapid clinical translation, particularly against chronically experienced antigens such as persistent infections or tumour-associated antigens in older people.

\section{Abbreviations}

CASAC: Combined Adjuvant for Synergistic Activation of Cellular Immunity; CFA: Complete Freund's Adjuvant; DC: Dendritic Cell; IFA: Incomplete

Freund's Adjuvant; IFN: Interferon; mAb: Monoclonal Antibody;

OVA: Ovalbumin; SIL: SIINFEKL; SVL: SVYDFFVWL; TLR: Toll-Like Receptor;

TRP-2: Tyrosinase-Related Protein 2.

\section{Competing interests}

The authors declare that they have no competing interests. 


\section{Authors' contributions}

GJT participated in design of the study, performed vaccination studies and analysed data. KI analysed data and wrote the manuscript. EA, RQP and SJW performed vaccination studies and analysed data. PK, AN and PMH participated in design of the study. KMLG helped to draft the manuscript. LDB participated in design of the study, performed vaccination studies, analysed data and helped to draft the manuscript. FF designed the study, analysed data and helped to draft the manuscript. All authors have read and approved the final manuscript.

\section{Acknowledgements}

This study was supported by a Programme Grant from the Leukaemia \& Lymphoma Research in UK and The Leukemia \& Lymphoma Society, USA. The research was also supported by the National Institute for Health Research (NIHR) Biomedical Research Centre (BRC) award to the Institute of Psychiatry in partnership with King's College Hospital NHS Trust and King's College London, and the Experimental Cancer Medicine Centre at King's College London. We would also like to thank Dr. Francesco Grimaldi for statistical analysis and Dr. Amanda Wilson for technical support.

\section{Author details}

${ }^{1}$ Department of Haematological Medicine, King's College London, Rayne Institute, London, UK. ${ }^{2}$ Institute for Research in Molecular Medicine, Universiti Sains Malaysia, George town, Malaysia. ${ }^{3}$ Medical Research Council and Asthma UK Centre in Allergic Mechanisms of Asthma, King's College London, Guy's Hospital, London, UK. Division of Transplant and Mucosal Cell Biology, King's College London, London, UK. ${ }^{5}$ Department of Medicine, University of California, San Francisco School of Medicine, San Francisco, USA.

Received: 9 March 2015 Accepted: 8 June 2015

Published online: 25 June 2015

\section{References}

1. Gavazzi G, Krause KH. Ageing and infection. Lancet Infect Dis. 2002;2:659-66.

2. Derhovanessian E, Pawelec G. Vaccination in the elderly. Microb Biotechnol. 2012:5:226-32.

3. Myers CE, Mirza NN, Lustgarten J. Immunity, cancer and aging: lessons from mouse models. Aging Dis. 2011;2:512-23.

4. Aspinall R, Del Giudice G, Effros RB, Grubeck-Loebenstein B, Sambhara S. Challenges for vaccination in the elderly. Immun Ageing. 2007;4:9.

5. Weiskopf D, Weinberger B, Grubeck-Loebenstein B. The aging of the immune system. Transpl Int. 2009;22:1041-50.

6. Mifsud EJ, Tan AC, Jackson DC. TLR agonists as modulators of the innate immune response and their potential as agents against infectious disease. Front Immunol. 2014;5:79.

7. Renshaw M, Rockwell J, Engleman C, Gewirtz A, Katz J, Sambhara S. Cutting edge: impaired Toll-like receptor expression and function in aging. J Immunol. 2002;169:4697-701.

8. Tan SY, Cavanagh LL, d'Advigor W, Shackel N, de St F, Groth B. Phenotype and functions of conventional dendritic cells are not compromised in aged mice. Immunol Cell Biol. 2012;90:722-32.

9. Zhu Q, Egelston C, Vivekanandhan A, Uematsu S, Akira S, Klinman DM, et al. Toll-like receptor ligands synergize through distinct dendritic cell pathways to induce T cell responses: implications for vaccines. Proc Natl Acad Sci U S A. 2008;105:16260-5.

10. Moody MA, Santra S, Vandergrift NA, Sutherland LL, Gurley TC, Drinker MS, et al. Toll-like receptor $7 / 8$ (TLR7/8) and TLR9 agonists cooperate to enhance HIV-1 envelope antibody responses in rhesus macaques. J Virol. 2014;88:3329-39.

11. Park H, Adamson L, Ha T, Mullen K, Hagen SI, Nogueron A, et al. Polyinosinic-polycytidylic acid is the most effective TLR adjuvant for SIV Gag protein-induced T cell responses in nonhuman primates. J Immunol. 2013;190:4103-15.

12. Tarhini AA, Butterfield LH, Shuai Y, Gooding WE, Kalinski P, Kirkwood JM. Differing patterns of circulating regulatory $T$ cells and myeloid-derived suppressor cells in metastatic melanoma patients receiving anti-CTLA4 antibody and interferon-alpha or TLR-9 agonist and GM-CSF with peptide vaccination. J Immunother. 2012;35:702-10.

13. Goldinger SM, Dummer R, Baumgaertner P, Mihic-Probst D, Schwarz K, Hammann-Haenni A, et al. Nano-particle vaccination combined with TLR-7 and -9 ligands triggers memory and effector CD8(+) T-cell responses in melanoma patients. Eur J Immunol. 2012;42:3049-61.

14. Wells JW, Cowled CJ, Farzaneh F, Noble A. Combined triggering of dendritic cell receptors results in synergistic activation and potent cytotoxic immunity. J Immunol. 2008;181:3422-31.

15. Maue AC, Yager EJ, Swain SL, Woodland DL, Blackman MA, Haynes L. T-cel immunosenescence: lessons learned from mouse models of aging. Trends Immunol. 2009;30:301-5.

16. Linton PJ, Dorshkind K. Age-related changes in lymphocyte development and function. Nat Immunol. 2004;5:133-9.

17. Chen J, Flurkey K, Harrison DE. A reduced peripheral blood CD4(+) lymphocyte proportion is a consistent ageing phenotype. Mech Ageing Dev. 2002:123:145-53.

18. Decman V, Laidlaw BJ, Doering TA, Leng J, Ertl HC, Goldstein DR, et al. Defective CD8 T cell responses in aged mice are due to quantitative and qualitative changes in virus-specific precursors. J Immunol. 2012;188:1933-41.

19. Henson SM, Akbar AN. KLRG1-more than a marker for T cell senescence. Age (Dordr). 2009;31:285-91.

20. Hulseberg PD, Zozulya A, Chu HH, Triccas JA, Fabry Z, Sandor M. The same well-characterized T cell epitope SIINFEKL expressed in the context of a cytoplasmic or secreted protein in BCG induces different CD8+ T cell responses. Immunol Lett. 2010;130:36-42.

21. Maletto BA, Ropolo AS, Liscovsky MV, Alignani DO, Glocker M, PistoresiPalencia MC. CpG oligodeoxinucleotides functions as an effective adjuvant in aged BALB/C mice. Clin Immunol. 2005;117:251-61.

22. Gravecamp C, Chandra D. Aging and cancer vaccines. Crit Rev Oncog. 2013;18:585-95.

23. Escors D. Tumour immunogenicity, antigen presentation and immunological barriers in cancer immunotherapy. New J Sci. 2014;2014.

24. Haynes L, Eaton SM, Burns EM, Rincon M, Swain SL. Inflammatory cytokines overcome age-related defects in CD4 T cell responses in vivo. J Immunol. 2004;172:5194-9.

25. Qin W, Jiang J, Chen Q, Yang N, Wang Y, Wei X, et al. CpG ODN enhances immunization effects of hepatitis B vaccine in aged mice. Cell Mol Immunol. 2004;1:148-52.

\section{Submit your next manuscript to BioMed Central and take full advantage of:}

- Convenient online submission

- Thorough peer review

- No space constraints or color figure charges

- Immediate publication on acceptance

- Inclusion in PubMed, CAS, Scopus and Google Scholar

- Research which is freely available for redistribution 